\title{
ENDOGENOUS PRODUCTION OF FIXED ACID AND THE MEASUREMENT OF THE NET BALANCE OF ACID IN NORMAL SUBJECTS *
}

\author{
BY ARNOLD S. RELMAN, EDWARD J. LENNON † AND JACOB LEMANN, JR. \\ WITH THE TECHNICAL ASSISTANCE OF HELEN P. CONNORS \\ (From the Evans Memorial Department of Clinical Research, Massachusetts Memorial \\ Hospitals, and the Department of Medicine, Boston University School of Medicine, \\ Boston, Mass.)
}

(Submitted for publication January 30, 1961; accepted March 24, 1961)

It is commonly assumed that one of the essential functions of the kidney is to maintain acidbase balance by excreting an amount of acid equivalent to the net quantity of protons released from fixed (i.e., nonvolatile) endogenous acids. Excretion of acid in the urine is easily measured. Therefore, if the net rate of production of fixed acids could also be measured independently, it might be possible to evaluate the external acid balance of the body in the same manner as the balance of mineral elements or nitrogen. In the normal steady state, the net excretion of acid in the urine (titratable acid plus ammonium, minus bicarbonate) would be expected to equal the sum of the nonmetabolized acids ingested plus those endogenously produced. Except for clinical situations in which stool losses of alkali or acid might also require consideration, all metabolic disturbances of the net acid-base balance of the body would thus be quantitatively determined by the difference between the acid ingested or endogenously produced and that excreted in the urine.

At present, however, there is no clear definition of all the sources of endogenous fixed acids nor does there exist any satisfactory method for accurately quantitating the net acid load independently of measurements of renal acid excretion. It is sometimes assumed that it is the calculated "acidity" or "alkalinity" of the diet "ash" which normally determines the endogenous load of fixed acids. This calculation, based simply on the discrepancy between mineral cations and the chloride, phosphorus and sulfur of the diet, has theoretical as well as practical defects (1-4), and does not in fact correlate well with the rate of acid excretion (5).

Hunt has recently adduced evidence to support

* Supported by Public Health Service Grant A-3140.

$\dagger$ Trainee of the National Institute of Arthritis and Metabolic Diseases. his suggestion that acid derived from the oxidation of organic sulfur to sulfate constitutes the major, if not the sole, source of fixed acid (5). In subsequent experiments from this laboratory (6) a detailed study was made of the acidifying effects of large oral methionine loads. It was found that the increased oxidation of organic sulfur to sulfate was accompanied by the systemic release of approximately equivalent quantities of protons, which ultimately were excreted in the urine. In many of Hunt's experiments, however, net acid excretion in the steady state was significantly greater than the measured excretion of sulfate. In our own studies, in which a natural soy flour, rich in potassium, was employed as the nitrogen source, net excretion of acid in the steady state prior to loading with methionine always was found to be approximately 20 to 30 per cent less than the excretion of sulfate (6). It thus appeared that the net endogenous production of fixed acid could not be equated solely with sulfate production.

The present study was therefore designed to investigate the normal sources of fixed acid more thoroughly. A new liquid-formula diet was devised which utilized a purified soy phosphoprotein virtually free of mineral cations. This made it possible to measure the acid contribution from the dietary protein more precisely. It was then found that the discrepancy between sulfate production and the excretion of net acid in the steady state could be quantitatively accounted for by the sum of the total organic acids in the urine plus the acid derived from the combustible cations neutralizing the phosphate groups in the protein fed. It was therefore concluded that the net production of endogenous fixed acids with the present diet was determined by the sum of : $a$ ) the oxidation of organic sulfur in the fed protein, $b$ ) the liberation of excess protons from the cations covering the 
phosphate radicals in the protein, and $c$ ) the endogenous formation of unmetabolized organic acids. The existence of an apparent physiologic balance between acid excretion and the production of fixed acid measured in this way was also demonstrated in a few relatively prolonged balance studies in which predictable changes in acid balance were temporarily induced by experimental alteration of the excretion or net production of acid.

\section{METHODS AND MATERIALS}

Ten balance studies were performed on 9 healthy young adult males. Liquid-formula diets were used which provided 35 to 40 calories and 0.8 to $1.0 \mathrm{~g}$ protein per $\mathrm{kg}$ body weight per day. Corn oil, glucose and dextrin served as sources of fat and carbohydrate. A pure soybean protein was used as the protein source. According to the manufacturer, this protein ${ }^{1}$ is essentially uniform by electrophoresis. It is virtually free of minerals other than phosphorus as shown by the following analyses: sodium, $1 \mathrm{mEq} / 100 \mathrm{~g}$; potassium, $3 \mathrm{mEq} / 100 \mathrm{~g}$; calcium, $<0.1 \mathrm{mEq} / 100 \mathrm{~g}$; magnesium, ${ }^{2}<0.1 \mathrm{mEq} / 100 \mathrm{~g}$; chloride, $<1 \mathrm{mEq} / 100 \mathrm{~g}$; phosphorus, 17 mmoles $/ 100 \mathrm{~g}$ ( 0.53 per cent $)$.

This protein was prepared at its isoelectric $\mathrm{pH}(5.0$ to 5.2) and does not disperse well in water. In 7 balances L-arginine (free-base), in quantities ranging from 25 to 57 mmoles per day ( 0.46 to 0.64 mmoles per $g$ protein), was used to raise the $\mathrm{pH}$ of the diet mixture to approximately 7.0 and thus effect dispersion of the protein. In one subject small amounts of ammonium hydroxide were used instead of arginine. In the remaining 2 balances the protein was dispersed by the addition of $\mathrm{Ca}(\mathrm{OH})_{2}$ and $\mathrm{Mg}(\mathrm{OH})_{2}$, as described in the following paragraph.

In all of the studies except those two in which $\mathrm{Ca}(\mathrm{OH})_{2}$ and $\mathrm{Mg}(\mathrm{OH})_{2}$ were given, the calculated acid derived from the phosphoprotein was added to the acid production measured as urinary inorganic sulfate and organic acids. This calculation was made on the assumption that the phosphate esters present in the protein were completely hydrolzed and the covering cations completely metabolized. Metabolism of an organic monophosphate ester does not necessarily yield protons. This result will depend upon the nature of the cationic group neutralizing the charge on the phosphate residues. At the isoelectric $\mathrm{pH}$ of the protein, phosphate groups are neutralized by protons or cationic amino groups. When arginine freebase or $\mathrm{NH}_{4} \mathrm{OH}$ is used to raise the $\mathrm{pH}$ of the isoelectric protein (as was the case in 8 of the present balance studies), the cations neutralizing the phosphate charges are combustible and hence metabolism of these cations will ultimately yield excess protons, just as if the isoelectric protein had been fed. In either case, the number of

1 "J-protein-100" kindly made available by the J. R. Short Milling Co., Chicago, Ill.

2 Magnesium analyses through the courtesy of Dr. W. Wacker, Peter Bent Brigham Hospital. protons released can be calculated by knowing the number of phosphate residues present, the $\mathrm{pK}^{\prime}$ of the phosphate and the final $\mathrm{pH}$ of the medium. Thus, with reference to the excellular $\mathrm{pH}(7.40)$, each mole of phosphorus fed would be expected to yield 1.8 equivalents of acid $\left(\mathrm{pK}_{2}^{\prime}\right.$ of phosphoric acid $\left.=6.8\right)$. If $\mathrm{Ca}(\mathrm{OH})_{2}$ or $\mathrm{Mg}(\mathrm{OH})_{2}$ is used to raise the $\mathrm{pH}$ of the protein, the cation "covering" the phosphate $\left(\mathrm{Mg}^{++}\right.$or $\left.\mathrm{Ca}^{++}\right)$is not combustible, and hence no protons will be released. In the two experiments in which $\mathrm{Ca}(\mathrm{OH})_{2}$ and $\mathrm{Mg}(\mathrm{OH})_{2}$ were given instead of arginine, the amount of alkali added was equal to the calculated excess of $\mathrm{H}^{+}$which is released if a combustible alkali such as ammonium hydroxide or arginine free-base is used to disperse the protein. Under these circumstances, therefore, the acidifying effect of the arginine phosphate or ammonium phosphate is avoided, and the hydrolysis and metabolism of the phosphate residues contribute no endogenous acid. It should be noted that, when arginine or ammonium phosphate is fed, it is not the phosphate residues but rather the combustible cations neutralizing these residues which give rise to the acid. Nevertheless, the quantity of acid so released can be calculated only from a consideration of the number of phosphate residues in the protein fed. (Any arginine or ammonia added to the phosphoprotein in excess of this number of residues does not give rise to acid.) Any noncombustible anionic residue on the protein would play the same role here as the phosphate, except that the $\mathrm{pK}$ of the residue determines what proportion of the protons yielded by metabolism of the combustible cations will continue to be held by the anionic residue at body fluid $\mathrm{pH}$ and what proportion will be given up to be handled by the physiological mechanisms for acid excretion.

The soybean protein contained adequate amounts of all the essential amino acids except methionine, so that a supplement of $1 \mathrm{~g}$ of DL- or L-methionine was provided daily in the basic diets. In addition, 50 to $80 \mathrm{mEq}$ of potassium chloride and 90 to $200 \mathrm{mEq}$ of sodium chloride per day were added to the diets. In 2 experiments 15 mmoles per day of calcium phosphate $\left(\right.$ as $\mathrm{CaHPO}_{4}$ ) was also added. In these 2 studies correction was made for the alkali thus fed, arbitrarily assuming virtually complete absorption. Each subject took 2 multiple vitamin capsules daily and, to prevent diarrhea, they also were given small doses of deodorized tincture of opium. All stools were formed, but soft in consistency.

Each study was preceded by a 2-day period of adaptation to the standard diet. The balance then began with a control period lasting 3 to 8 days. In 6 experiments only these control observations were made. In the other 4 studies the control period was followed by an experimental period lasting 5 to 7 days during which the following changes in the control regimen were made:a) 1 subject received sodium bicarbonate, $70 \mathrm{mEq}$ per day in divided doses, in addition to the control diet; $b$ ) 2 subjects received oral loads of neutral $(\mathrm{pH} 7.40)$ sodium orthophosphate, the phosphate mixture replacing a part of the chloride in the control diet, with sodium intake being kept at the control level; and c) 1 subject was given acetazolamide, $1.0 \mathrm{~g}$ daily in divided doses, in addi- 


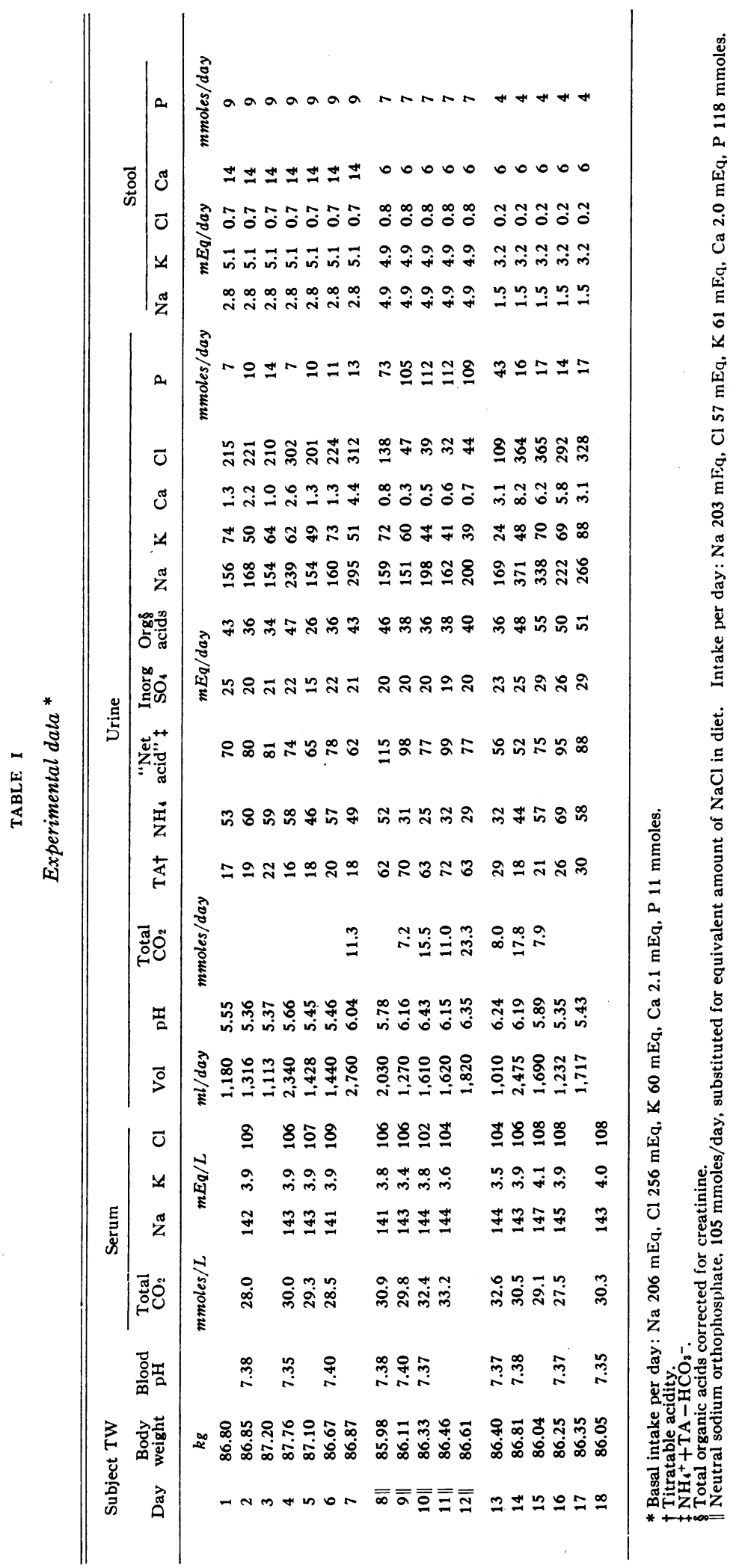


tion to the control diet. In each of these 4 studies the experimental periods were followed by recovery periods of 4 to 6 days' duration.

Further details of the balance technique in use in this laboratory, as well as descriptions of most of the methods used for the analyses of diets, urine, feces and blood have previously been reported $(6,7)$. In the present experiments "organic acids" in urine were measured by the Van Slyke and Palmer method (8), modified as follows. Phosphate was removed by mechanical shaking for 30 minutes with added calcium hydroxide powder. Remaining carbonate was then eliminated by addition of $\mathrm{HCl}$ until the $\mathrm{pH}$ was exactly at 2.70. A Cambridge model $\mathrm{R}$ $\mathrm{pH}$ meter with dipping electrodes and a constant temperature bath at $37^{\circ} \mathrm{C}$ was employed for this purpose. "Organic acids" were then determined by titrating from $\mathrm{pH}$ 2.70 to $\mathrm{pH} 7.40$, with $0.1 \mathrm{~N} \mathrm{NaOH}$. Correction was made for creatinine. Additional techniques, used in a few studies, included: $a$ ) calcium, by the method of Clark and Collip (9) and $b$ ) citrate, by a pentabromacetone method (10).

\section{RESULTS}

I. Control observations during the steady state (ten subjects)

A. Experimental data. Electrolyte balances were carried out in ten subjects under steady state conditions. In one, this period lasted only 3 days, and in another 5 days, but in the others the control observations lasted 6 to 8 days. Complete analytical data from one experiment which began with a control period of 7 days are shown in Table I. In this study, as well as in the other nine, serum electrolyte concentrations and $\mathrm{CO}_{2}$ content and blood $\mathrm{pH}$ were essentially constant during the control periods. As shown in Table I, the urine $\mathrm{pH}$ and the daily excretion of all urinary constituents were also relatively steady. Fecal excretion of sodium, potassium and chloride was low. Fecal calcium varied in six experiments from 10 to $27 \mathrm{mEq}$ per day and fecal phosphorus ranged from 6 to 11 mmoles per day.

Cumulative changes in weight were small and variable $(-1.02$ to $+0.59 \mathrm{~kg})$. Small positive cumulative sodium and chloride balances were noted in all subjects, consistent with the expected skin losses. Although not shown in the experiment of Table I, nitrogen balances were carried out in three subjects. Cumulative nitrogen balances ranged from -1.5 to $+3.3 \mathrm{~g}$. Cumulative potassium balances, uncorrected for nitrogen, varied from -13 to $-109 \mathrm{mEq}$. Cumulative calcium balance varied from -111 to $+6 \mathrm{mEq}$, and cumulative phosphorus balance ranged from
-60 to +2 mmoles, the large negative balances resulting from stool losses in the subjects whose diets did not contain added calcium and phosphorus.

$B$. Derived data. The daily net excretion of acid (calculated as titratable acid plus ammonium minus bicarbonate) was approximately constant in every subject, as exemplified by the data in Table I, in the column headed "net acid." The excretion of inorganic sulfate was always less than half the net acid excretion, but it was noted that in each case the discrepancy between sulfate and acid excretion was approximately equal to the total "organic acid" excretion plus the calculated acid derived from dietary protein phosphorus. In each subject there were significant daily fluctuations in this relationship, as illustrated by the data in Table I, but on a cumulative basis the excretion of net acid for the entire control period was always very nearly equal to the sum of these three quantities. Table II presents a comparison of the cumulative excretion of net acid with the sum of excreted sulfate plus "organic acids" plus the calculated acid derived from the cation covering the phosphate residues in the protein. This comparison is made for the control periods only, in each of the ten subjects. The close agreement between acid excretion and production is apparent, the mean discrepancy being $-0.4 \pm 8.9$ per cent. This result is also illustrated in the data in three individual subjects shown in the left-hand sections of Figures 1-3. An explanation of the design of these Figures is given below.

TABLE II

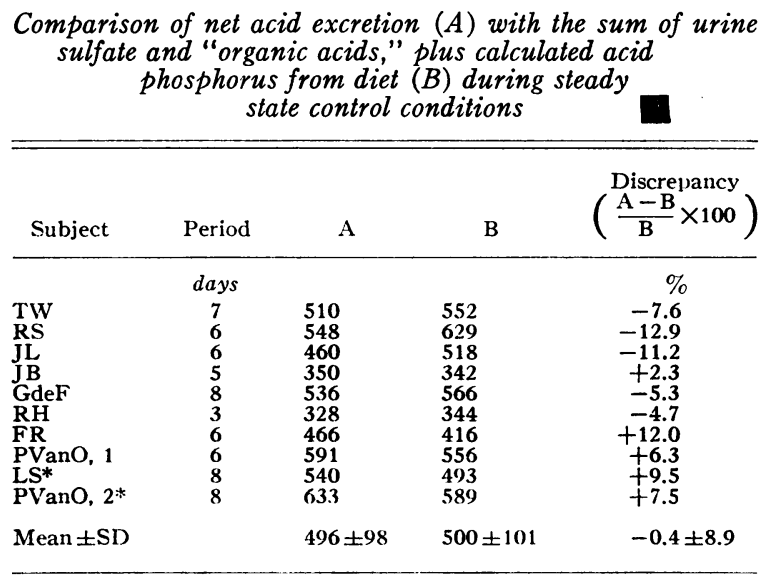

* Dietary phosphorus neutralized by $\mathrm{Ca}(\mathrm{OH})_{2}$ and $\mathrm{Mg}(\mathrm{OH})_{2}$, hence not included in calculation of acid production (column $\mathrm{B}$ ). 


\section{Effects of experimental changes in net acid production or acid excretion}

If we assume the existence of a steady state of acid-base balance during the control periods, the data of Table II seem to imply that the only significant sources of endogenous fixed acid in these experiments were the protons released during: a) the oxidation of organic sulfur to sulfate, $b$ ) the generation of organic acids, and $c$ ) the combustion of the disposable cations covering phosphate residues in the dietary protein. In an attempt to determine whether acid-base equilibrium measured in this way could be demonstrated over even longer periods, and to ascertain whether induced changes in net acid production or excretion would have quantitatively predictable effects on this equilibrium, four additional experiments were carried out.

A. Sodium bicarbonate. In the first such experiment, an amount of sodium bicarbonate was administered which was equal to the estimated rate of acid production during the control period. The essential observations made in this study are summarized in Figure 1. In the upper half of the figure are shown the values for serum $\mathrm{CO}_{2}$ content and 24-hour urine $\mathrm{pH}$. In the lower half is shown the "acid" balance, plotted in the conventional manner of an electrolyte or nitrogen balance. Acid production, calculated in the manner already described, is plotted as a heavy line measured downward from the zero axis. Net acid excretion is measured upward from the line indicating acid production (diagonally-shaded area). Thus, clear areas below the zero axis represent positive proton balance, and extensions of the shaded area above the zero axis define a negative proton balance.

During the control period of this study, the average acid production and excretion was approximately $70 \mathrm{mEq}$ per day and, as shown in the figure, net proton balance was virtually zero. Serum $\mathrm{CO}_{2}$ content and blood $\mathrm{pH}$ were essentially constant, as was daily urine $\mathrm{pH}$. After this, 70 $\mathrm{mEq}$ of $\mathrm{NaHCO}_{3}$ was added to the daily diet for 7 days, as shown by the stippled area in the figure. Since the measured production of acid and the ingestion of protein phosphate remained virtually constant throughout the loading period, as shown by the dashed line, the not effective acid produc-

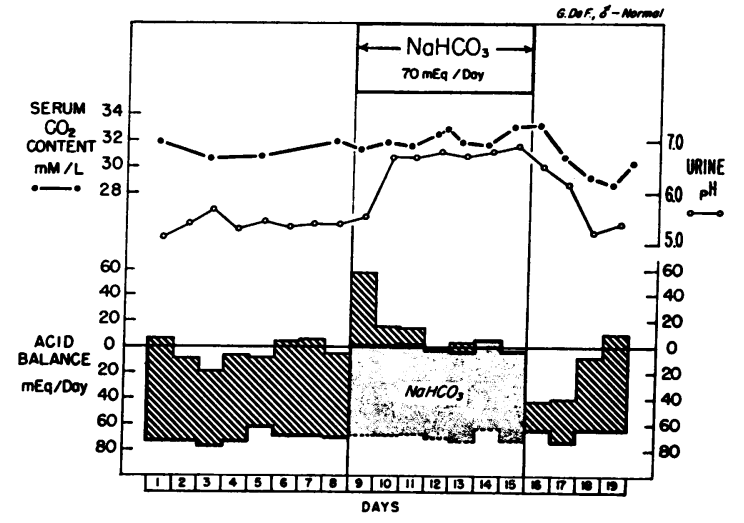

Fig. 1. Net external acid balance, serum $\mathrm{CO}_{2}$ CONTENT AND URINE PH IN A NORMAL SUBJECT GIVEN $\mathrm{NAHCO}_{3}$ FOR 7 DAYs. In this and subsequent figures, acid production is plotted downward from the zero line and net acid excretion in the urine is plotted as a diagonally-shaded column back up from the heavy line indicating acid production. Thus, a clear area below the zero line indicates a positive acid balance, and extension of the shaded area above the zero line indicates a negative acid balance. During the experimental period acid production is indicated by the dashed line but, due to the administration of $\mathrm{NaHCO}_{3}$, net acid production is 70 $\mathrm{mEq}$ per day less than this, as shown by the heavy solid line. Urine acid excretion is plotted upward from this line.

tion was zero during this time. This is indicated in the figure by the heavy line which is nearly superimposed upon the zero axis. Acid excretion is plotted upward from this heavy line. During the first 3 days cumulated net proton balance was $-85 \mathrm{mEq}$, because acid excretion did not cease immediately. Thereafter, acid excretion was essentially zero during the last 4 days of the experimental period. The reduction in net acid excretion was mainly accounted for by reductions in the excretion of ammonium and titratable acid. Although urine $\mathrm{pH}$ rose to approximately 6.6 , no more than $28 \mathrm{mEq}$ per day of the administered bicarbonate load was excreted as such in the urine. Serum $\mathrm{CO}_{2}$ content rose slightly.

When the administration of sodium bicarbonate was stopped, the net effective acid production immediately returned to control, but the acid excretion remained low for 2 more days before returning to the control rate. During this period the net retention of protons was $78 \mathrm{mEq}$, an amount closely approximating the net loss of 85 $\mathrm{mEq}$ of acid which had occurred at the beginning of the period of alkali administration. At the end 
of 19 days, when serum $\mathrm{CO}_{2}$ content and urine $\mathrm{pH}$ had returned to control, the total cumulative production of fixed acid (corrected for the bicarbonate fed) was $827 \mathrm{mEq}$, as compared with a cumulative net acid excretion of $806 \mathrm{mEq}$.

B. Neutral orthophosphate. The purpose of these two experiments was to increase acid excretion without changing acid production. This was accomplished by the administration of extra urinary buffer in the form of neutral inorganic phosphate. If measured acid production were to remain constant, this should result in a negative proton balance and the development of metabolic alkalosis. Furthermore, we would expect restoration of acid-base balance after cessation of phosphate loading to be accompanied by a demonstrably positive proton balance of approximately equal magnitude.

Subject TW (Table I) and Subject P VanO (No. 1, Figure 2) were given oral loads of neutral ( $\mathrm{pH} 7.40$ ) sodium orthophosphate for 5 days, the phosphate replacing part of the chloride in the control intake and the sodium intake remaining constant. After control periods, in which acid production and excretion in both studies were approximately equal, the phosphate load resulted in an immediate increase in net acid excretion. The rise in acid excretion was due entirely to increased titratable acid (Table I), which occurred despite a rise in urine $\mathrm{pH}$ and a reduction in ammonium excretion.

Since there was no significant change in calculated acid production, the initially increased ex-

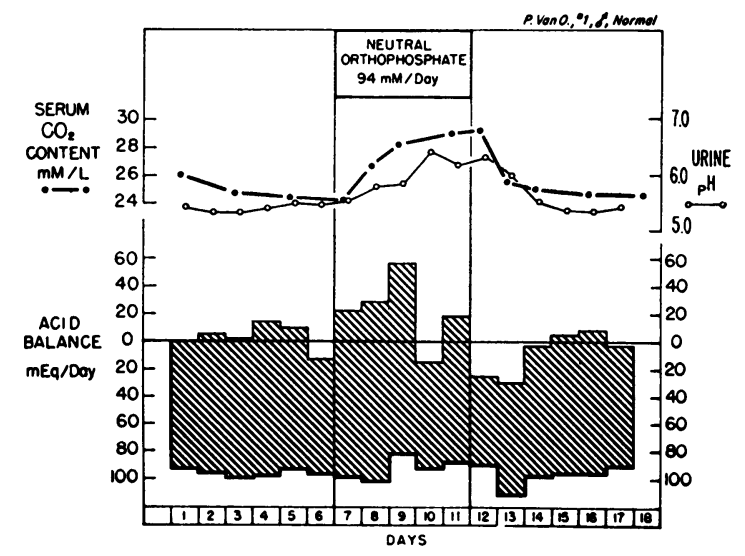

Fig. 2. The effect of feeding neutral sodium pilOSPHATE ON NET EXTERNAL ACID BALANCE, SERUM CO, CONTENT AND URINE PH. cretion of net acid resulted in a negative acid balance. Cumulative balance of acid during the loading period was $-66 \mathrm{mEq}$ in $\mathrm{TW}$ and -112 $\mathrm{mEq}$ in $\mathrm{P}$ VanO. As would be predicted, there was a rise in serum $\mathrm{CO}_{2}$ content in both cases, the final level being approximately 3 mmoles per $\mathrm{L}$ above control in TW and 5 above control in $\mathrm{P}$ VanO.

When phosphate loading was stopped, urinary excretion of phosphate immediately returned to control. For the first 2 days of the recovery period urine $\mathrm{pH}$ remained somewhat elevated and ammonium excretion was slightly reduced. Therefore, net acid excretion dropped sharply and acid balance became positive. Cumulative retention of acid during the recovery period was +106 $\mathrm{mEq}$ in TW and $+48 \mathrm{mEq}$ in $\mathrm{P}$ VanO. Serum $\mathrm{CO}_{2}$ returned to control values and approximate equilibrium between production and excretion of acid was ultimately restored. For the entire period of study, cumulated acid production in TW was $1,421 \mathrm{mEq}$ and cumulated excretion was $1,342 \mathrm{mEq}$. In the other subject (Figure 2) total production was $1,618 \mathrm{mEq}$ and total excretion 1,693 .

C. Acetazolamide. This experiment was designed to reduce renal excretion of acid without altering acid production. After a control period, the subject was given $250 \mathrm{mg}$ of acetazolamide four times daily by mouth for 7 days. Administration of the drug produced a large diuresis of bicarbonate, and therefore net acid excretion was negative on the first day (Figure 3 ). This is illustrated in the figure by the dotted bar extending in a downward, or negative, direction from the level of acid production. Net retention of acid on this day was $+226 \mathrm{mEq}$, and during this time serum $\mathrm{CO}_{2}$ content fell from 31 to 24 mmoles per L. With continuing administration of drug, bicarbonate diuresis waned, and net excretion of acid became positive. However, acid balance continued to be slightly positive for the next few days and serum $\mathrm{CO}_{2}$ content continued to fall slightly, reaching a minimal level of 21 mmoles per $\mathrm{L}$. During the last 2 days of treatment the average acid balance was virtually zero and there was no further fall in serum $\mathrm{CO}_{2}$ content.

On cessation of drug, excretion of net acid increased and exceeded acid production. Thus, during the last 4 days, acid balance was markedly 


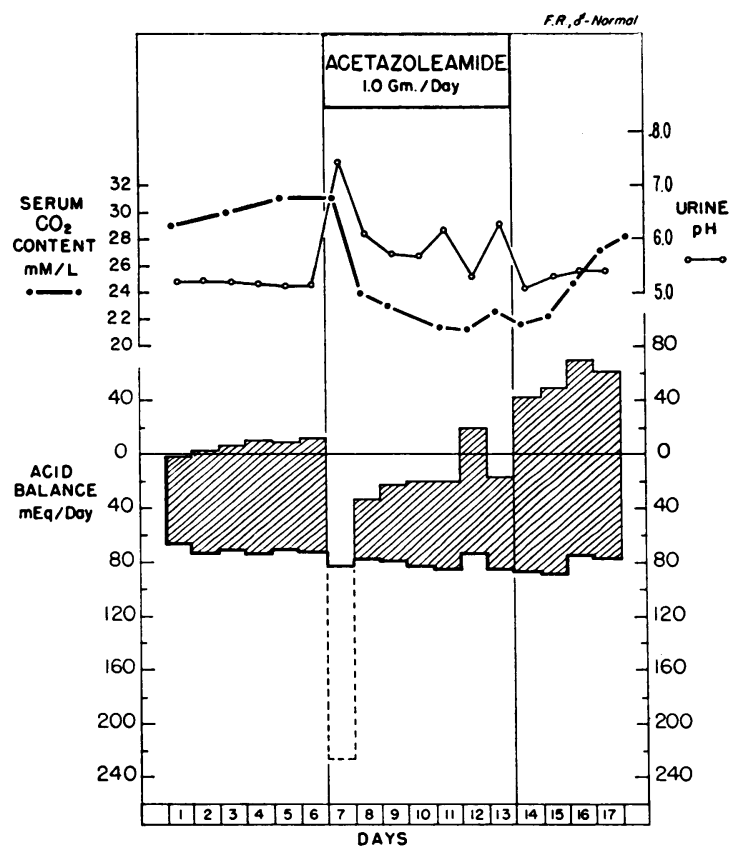

Fig. 3. The efFect of administration of aCetazolAMIDE ON NET EXTERNAL ACID BALANCE, SERUM CO: CONTENT AND URINe pH. On the first day of drug administration net acid excretion was negative, due to the loss of urinary bicarbonate. This is plotted as a dashed line downward from the heavy solid line indicating acid production. The net positive acid balance on that day is represented by the total distance between the dashed line and the baseline.

negative and serum $\mathrm{CO}_{2}$ content was rising steadily.

On the fifth day of recovery the subject developed a gastroenteritis, and the study had to be terminated before the control state of acid-base equilibrium could be restored. At this time the cumulative acid production for the total balance was $1,340 \mathrm{mEq}$, as compared with a cumulative acid excretion of $1,259 \mathrm{mEq}$. The net balance of acid was therefore $+81 \mathrm{mEq}$; the final serum $\mathrm{CO}_{2}$ content was 28.2 , as compared with the two final control values of 31 mmoles per $\mathrm{L}$.

\section{DISCUSSION}

Most authorities assume that endogenous acid production results largely from the oxidation of organic sulfur- and phosphorus-containing compounds to inorganic sulfate and phosphate (11, 12), but until the recent study by Hunt (5) there had been no attempts at quantitative verification of any part of this hypothesis. Using various types of natural diets, Hunt found that net excretion of acid could be mainly accounted for by inorganic sulfate but observed no correlation between acid excretion and dietary phosphorus. $\mathrm{He}$ therefore suggested that endogenous acids arose almost entirely from the oxidation of sulfur; however, in several of his experiments sulfate was significantly less than net acid excretion. This discrepancy would have been even greater had the determination of "titratable acidity" been carried to the usual endpoint of $\mathrm{pH} 7.4$ instead of to $\mathrm{pH}$ 7.0. A significant fraction of acid production therefore remained to be identified.

Recent experiments in this laboratory (6) have provided more direct quantitative evidence for the relationship of the oxidation of organic sulfur to fixed acid production. The results differed from those of Hunt in revealing the excretion of sulfate in the steady state to be significantly greater than the net excretion of acid. The explanation probably resided in the fact that the natural soybean flour used in those initial experiments contained potential alkali in the form of potassium, calcium and magnesium salts of the carboxyl groups in the protein. Since virtually all natural foods can be expected to contain variable and probably indeterminate quantities of "hidden alkali" in the form of such salts of metabolizable anions, it was decided to restudy the problem in the experiments reported here, with a synthetic diet and a protein source essentially free of fixed cation.

The present results indicate that less than half of net acid excretion in the steady state was due to oxidation of sulfur. The discrepancy could be almost quantitatively accounted for by the total organic acids in the urine, plus the calculated acid derived from the protein phosphorus in the diet. This seems to imply that under these experimental conditions the only significant sources of endogenous fixed acid were the protons released during: a) the oxidation of organic sulfur to sulfate (6), $b)$ the generation of nonmetabolized organic acids, and $c$ ) the combustion of the disposable cation neutralizing phosphate residues in the dietary protein.

In the classical descriptions of the "acid-base" balance of the urine, organic acid anions were considered to represent "acid," but only in the sense that all anions were defined as "acids" and all cations as "bases" $(13,14)$. Such an approach 
does not permit calculation of the actual net rate of fixed acid production and cannot logically be applied to a description of the acid balance of the body $(3,4,15)$. It is well recognized that in certain abnormal states, such as diabetic ketosis, endogenous production of organic acids constitutes a major source of the acid load. In the present experiments, however, the special significance of urinary organic acids as one of the major sources of normal endogenous release of protons is clearly demonstrated. It seems reasonable that they should have this significance, for the organic acid anions normally appearing in the urine must represent acids produced during metabolism, which escape complete oxidation to $\mathrm{CO}_{2}$ and $\mathrm{H}_{2} \mathrm{O}$ and which therefore must have donated their protons to body buffers.

It should be noted that the relatively small fraction of excreted organic acids which appears in the urine as free acid (i.e., that fraction which is titrated between the $\mathrm{pH}$ of urine and the $\mathrm{pH}$ of plasma) does not contribute its protons to the body, and properly should be subtracted from the determination of "organic acids" in the calculation of acid production; but, since this free acid fraction is also measured in the determination of titratable acidity, net acid excretion by the kidney is overestimated by the same amount, and thus the calculation of net proton balance is unaffected.

The Van Slyke and Palmer titration is not a precise method and certainly does not measure organic acids alone (8). It includes not only creatinine (which must be subtracted from the total measured value) but also small quantities of amino acids and sulfate. The apparent $\mathrm{pK}$ for the carboxyl groups of the various amino acids ranges from approximately 1.8 to 2.4. Assuming normal urinary excretion of amino acids (up to 15 mmoles), partial titration of these carboxyl groups might overestimate organic acids by as much as $5 \mathrm{mEq}$ per day. Since the apparent $\mathrm{pK}_{2}$ for sulfuric acid is approximately 1.7 , some 10 per cent of the urinary sulfate would also be titrated between 2.7 and 7.4, and in the present studies this would tend to overestimate organic acids by another 2 to $4 \mathrm{mEq}$ per day. On the other hand, it has been reported (and we have confirmed) that nearly half of the urinary citrate may be lost during the "organic acid" titration, as a result of precipitation with calcium (16). During two of the present studies urinary citrate was found to range from 5 to $8 \mathrm{mEq}$ per day, and it can therefore be estimated that the Van Slyke and Palmer titration probably underestimated citrate by about 2 to $4 \mathrm{mEq}$ per day.

Considered together, all of these small errors in both directions tend approximately to cancel each other out. Although there are probably other sources of minor error in the method which have not been discussed, it appears that under the present conditions the Van Slyke and Palmer titration provides an approximate but reasonably satisfactory estimate of the contribution of organic acids to the generation of fixed acid. It is worth noting in this context that when the diet consists of natural foods containing organic acids the relationship of these compounds to net acid production may become considerably more complex than that described here. Neutral salts of metabolizable acids would cause removal of hydrogen ions from the body and thus would reduce net acid production without affecting the organic acid output in the urine. On the other hand, salts of noncombustible acid (e.g., benzoic or tartaric) would not affect acid production although they might well increase the total measured excretion of organic acids in the urine. Such considerations emphasize the importance of the synthetic diet in providing the conditions necessary for the accurate determination of net endogenous acid production.

In the present studies the presence of phosphate residues in the dietary protein appeared to be responsible for the third component of endogenous acid production. Previous opinion on the role of phosphorus in acid production has varied. Most of the earlier authorities $(1,2,11-14)$ had assumed that all dietary phosphorus contributed to acid production. More recently, however, Hunt (5), Christensen $(4,15)$ and others have pointed out that, since most phosphorus in natural foods exists already oxidized as the potassium, magnesium, calcium or sodium salts of organic phosphoric acid monoesters, hydrolysis of such esters would result in the formation of essentially neutral inorganic phosphate with no liberation of protons. ${ }^{3}$

\footnotetext{
3 Since organic phosphate monoesters in proteins probably have slightly lower $\mathrm{pK}_{2}^{\prime}$ values than inorganic phosphate (17) the cleavage of such neutral esters would probably have a slightly alkaline effect.
} 
The metabolism of phosphodiesters might be expected, on the other hand, to yield phosphoric acid. However, in most diets diester linkages would occur relatively infrequently and would not often make a significant contribution to acid production. In support of such reasoning, Hunt reported that he was unable to observe any constant relationship between dietary phosphorus and urinary excretion of acid.

In the experiments reported here, the only source of dietary organic phosphorus was the purified soy phosphoprotein which was virtually free of inorganic electrolytes. In contrast to the situation prevailing in most natural foods, the phosphate residues in the soyprotein used in eight of the ten balances were neutralized by combustible cations in the form of arginine $\left(\mathrm{R}^{-} \mathrm{NH}_{3}{ }^{+}\right)$or ammonium. Such cations, when metabolized, ultimately must yield protons (see discussion in Methods). In calculating the acid contribution from this source, it was assumed that metabolism and hydrolysis of dietary protein was complete and that the liberated phosphate residues were titrated to a $\mathrm{pH}$ of 7.4. That such assumptions were at least approximately true is indicated by the reasonably close agreement of acid excretion with the total acid production calculated in this manner (Table II).

The observations made during the course of the four relatively prolonged balance studies merit some final comment. In the bicarbonate experiment, the prompt fall in renal acid excretion to very close to zero levels (Figure 1) provides strong support for the idea that Subject GdeF was in fact in acid-base equilibrium prior to the bicarbonate load. In the two phosphate experiments a similar conclusion may be drawn from the fact that relatively small increments in net acid excretion were promptly followed by rises in serum $\mathrm{CO}_{2}$ content. The fact that adjustments in renal acid excretion following the bicarbonate or neutral phosphate load resulted in a final cumulative equality between calculated acid production and acid excretion in the urine is also of great interest, for it tends to indicate that administered or endogenous acid or alkali is not ordinarily excreted in significant quantities by any extrarenal route, such as the stool. A similar conclusion follows from the fact that essentially all of the extra endogenous acid derived from methionine could be recovered in the urine (6).

In all of the prolonged balance studies, the ob served relationships between acid balance and the serum $\mathrm{CO}_{2}$ content were entirely consistent with what would be expected from the interplay of two physiological variables such as acid production and excretion. Thus, whenever the net excretion of acid exceeded the calculated rate of production, serum $\mathrm{CO}_{2}$ content tended to rise and, conversely, whenever production exceeded excretion, the $\mathrm{CO}_{2}$ content fell.

In an earlier study of normal subjects given an acute acid load (18), it was demonstrated that calculation of acute changes in net acid balance was feasible, assuming a constant, though unknown, rate of endogenous acid production. The present results appear to offer a technique for measuring the actual net balance of protons and therefore may permit study of the absolute gain or loss of hydrogen ions under a variety of experimental and clinical situations. The method requires, however, that the subjects be in approximate nitrogen equilibrium, because catabolism of tissue protein would present difficulties in calculation of acid production similar to those already described with the use of natural dietary protein.

\section{SUMMARY AND CONCLUSIONS}

The purpose of this study was to determine whether it was possible to measure the total endogenous production of fixed acid and, by comparing this independently determined quantity with the net renal excretion of acid, to measure the net external acid balance of the body.

In a series of ten balance experiments, normal subjects in an apparently steady state were fed a liquid-formula diet which had as the nitrogen source a purified soy phosphoprotein essentially free of mineral cations. It was demonstrated that the net renal excretion of acid was closely matched by the sum of: $a$ ) inorganic sulfate in the urine, b) total "organic acids" in the urine, and $c$ ) the acid calculated to be released by the metabolism of the combustible cationic groups covering the phosphate residues in the dietary phosphoprotein. In three experiments net production or excretion of acid was temporarily altered and, at the end, when a steady state had been restored, the equivalence 
of cumulated acid excretion with the cumulated production of acid could again be demonstrated.

These observations are taken to mean that, under the present conditions, the total net production of fixed acid arose from the oxidation of organic sulfur, plus the production of nonmetabolized organic acids from neutral precursors, and the release of protons during the metabolism of the organic cations neutralizing phosphate esters or during the hydrolysis of phosphate diesters in the dietary phosphoprotein, or both. However, when noncombustible cations neutralize the phosphate residues, no acid production can be attributed to the presence of phosphate monoesters in the protein.

The relationship between acid production measured in this way and the renal excretion of acid appears to be that of a true physiological equilibrium. Provided that body composition remains relatively constant during the period of study, it should be possible to apply this technique to the direct measurement of the external balance of acid under a variety of experimental and clinical conditions.

\section{REFERENCES}

1. Shohl, A. T. Mineral Metabolism. New York, Reinhold, 1939, pp. 293-295.

2. Sherman, H. C. Chemistry of Food and Nutrition, 7th ed. New York, Macmillan, 1946, pp. 248-253.

3. Relman, A. S. What are "acids" and "bases"? Amer. J. Med. 1954, 17, 435.

4. Christensen, H. N. Diagnostic Biochemistry; Quantitative Distributions of Body Constituents and Their Physiological Interpretation. New York, Oxford Univ. Press, 1959, chap. 10.

5. Hunt, J. N. The influence of dietary sulphur on the urinary output of acid in man. Clin. Sci. 1956, 15, 119.
6. Lemann, J., Jr., and Relman, A. S. The relation of sulfur mctabolism to acid-base balance and electrolyte excretion: The effects of DL-methionine in normal man. J. clin. Invest. 1959, 38, 2215.

7. Relman, A. S., and Schwartz, W. B. The effect of DOCA on electrolyte balance in normal man and its relation to sodium chloride intake. Yale J. Biol. Med. 1952, 24, 540.

8. Van Slyke, D. D., and Palmer, W. W. Studies of acidosis. XVI. The titration of organic acids in urine. J. biol. Chem. 1920, 41, 567.

9. Clark, E. P., and Collip, J. B. A study of the Tisdall method for the determination of blood serum calcium with a suggested modification. J. biol. Chem. 1925, 63, 461.

10. Ettinger, R. H., Goldbaum, L. R., and Smith, L. H., Jr. A simplified photometric method for the determination of citrate in biological fluids. J. biol. Chem. 1952, 199, 531.

11. Peters, J. P., and Van Slyke, D. D. Quantitative Clinical Chemistry. Vol. I, Interpretations. Baltimore, Williams \& Wilkins, 1931, p. 964.

12. Smith, H. W. Principles of Renal Physiology. New York, Oxford Univ. Press, 1956, p. 134.

13. Gamble, J. L., Ross, G. S., and Tisdall, F. F. The metabolism of fixed base during fasting. J. biol. Chem. 1923, 57, 633.

14. Albright, F., and Reifenstein, E. C., Jr. The Parathyroid Glands and Metabolic Bone Disease. Baltimore, Williams \& Wilkins, 1948, pp. 241-247.

15. Christensen, H. N. Anions versus cations? Amer. J. Med. 1957, 23, 163.

16. Sherman, C. C., Mendel, L. B., and Smith, A. H. The metabolism of orally administered citric acid. J. biol. Chem. 1936, 113, 265.

17. Folsch, G., and Osterberg, R. The apparent acid ionization constants of some O-phosphorylated peptides and related compounds. J. biol. Chem. 1959, 234, 2298.

18. Schwartz, W. B., Jenson, R. L., and Relman, A. S. The disposition of acid administered to sodiumdepleted subjects: The renal response and the role of the whole body buffers. J. clin. Invest. 1954, 33, 587. 